\title{
Persistence of engineered nanoparticles in a municipal solid-waste incineration plant
}

\author{
Tobias Walser1, Ludwig K. Limbach², Robert Brogioli3 ${ }^{3}$ Esther Erismann ${ }^{4}$, Luca Flamigni, \\ Bodo Hattendorf ${ }^{3}$, Markus Juchli ${ }^{5}$, Frank Krumeich ${ }^{3}$, Christian Ludwig6, Karol Prikopsky ${ }^{4}$, \\ Michael Rossier ${ }^{2}$, Dominik Saner', Alfred Sigg ${ }^{4}$, Stefanie Hellweg', Detlef Günther ${ }^{3}$ \\ and Wendelin J. Stark ${ }^{2 \star}$
}

\begin{abstract}
More than 100 million tonnes of municipal solid waste are incinerated worldwide every year'. However, little is known about the fate of nanomaterials during incineration, even though the presence of engineered nanoparticles in waste is expected to grow ${ }^{2}$. Here, we show that cerium oxide nanoparticles introduced into a full-scale waste incineration plant bind loosely to solid residues from the combustion process and can be efficiently removed from flue gas using current filter technology. The nanoparticles were introduced either directly onto the waste before incineration or into the gas stream exiting the furnace of an incinerator that processes 200,000 tonnes of waste per year. Nanoparticles that attached to the surface of the solid residues did not become a fixed part of the residues and did not demonstrate any physical or chemical changes. Our observations show that although it is possible to incinerate waste without releasing nanoparticles into the atmosphere, the residues to which they bind eventually end up in landfills or recovered raw materials, confirming that there is a clear environmental need to develop degradable nanoparticles.
\end{abstract}

The amount of consumer goods containing engineered nanomaterials is expected to grow ${ }^{2}$, and the disposal of these products represents an increasing proportion of the over one billion metric tonnes of municipal solid waste disposed globally ${ }^{1}$. Although landfilling is still common practice in many countries, thermal waste treatment is becoming an important alternative. For example, China plans to expand its capacity for waste incineration from $3 \%$ in 2011 to $30 \%$ by 2020 (refs 3,4), and the European Commission has been phasing out the landfill of biodegradable waste through legislation ${ }^{5}$. These efforts aim to minimize the amount of untreated landfill waste.

Engineered nanoparticles are often designed to be evenly distributed, insoluble and stable when incorporated into consumer goods. However, these characteristics can pose problems when the nanoparticles enter the natural environment ${ }^{6}$. For example, the use of persistent chemicals such as fluoro-chloro-hydrocarbons in fridges has depleted the stratospheric ozone layer ${ }^{7}$, and the use of fibrous solids such as asbestos in building materials has resulted in high incidences of mesothelioma ${ }^{8}$. Furthermore, the widespread use of insecticides has seen various fluorinated compounds, dioxins and halogenated biphenyl compounds accumulate in the food web ${ }^{9}$. It is expected that exposure of the biosphere to persistent nanoparticles may also result in similar undesirable outcomes, so the best precautionary measure is to limit their presence and residence time in the environment. This means that there is a need for proper disposal of persistent nanoparticles.

With the growing interest in using persistent nanomaterials in products, we need information on the extent to which they are modified and later made bioavailable through incineration. Nanowaste is treated directly or indirectly. For instance, wastewater treatment plants efficiently transfer engineered nanoparticles from wastewater to sludge ${ }^{10,11}$, which is sometimes then incinerated. We do not yet know the fate and removal efficiency of nanoparticles in large-scale incinerators. A few attempts have been made to investigate individual flue gas cleaning steps, such as the electrostatic precipitator $^{12}$, or to model the release of engineered nanoparticles from incineration to air $^{13}$. However, because waste incinerators are complex systems that include interaction effects arising from heterogeneous waste matrices and changing process conditions, any model predictions and laboratory studies are of limited value and require verification by large-scale experiments ${ }^{14,15}$. We demonstrate this necessity for large-scale experiments through an additional set of small-scale ones, in which we account for the incineration behaviour of different size classes of engineered nanoparticles. Although the lower removal efficiency of nanoparticles in comparison to their larger counterparts has been modelled ${ }^{13}$, no study has followed the nanoparticles through the entire waste incineration chain. Therefore, all previous research has only analysed fragments of the waste incineration chain or developed models based on a few assumptions from small-scale studies, which do not necessarily reflect reality. In this Letter, we investigate the fate of engineered nanoparticles quantitatively and qualitatively in a large-scale experiment, and we account for the complex chemical environment with simultaneously occurring matrix effects that influence the behaviour of engineered nanoparticles during incineration.

In two separate cases we added engineered nanoparticles to the thermal waste treatment line of a large-scale incinerator with energy recovery, an electrostatic precipitator for the removal of fine particles, a selective non-catalytic reduction to reduce the $\mathrm{NO}_{x}$ concentration, and a wet flue gas cleaning system (wet scrubber) for further removal of particles (including heavy metals) and corrosive gases (Fig. 1, Supplementary Table S1, Supplementary Figs $\mathrm{S} 1-\mathrm{S} 3$ ). We chose nano- $\mathrm{CeO}_{2}$ with a hydrodynamic diameter mode of $80 \mathrm{~nm}$ because of its industrial relevance, relatively low background concentration and inertness. In case 1, nanoparticles were introduced by spraying a $0.2 \mathrm{~m}^{3}$ volume of nano- $\mathrm{CeO}_{2}$

\footnotetext{
Institute of Environmental Engineering, ETH Zurich, 8093 Zurich, Switzerland, ${ }^{2}$ Functional Materials Laboratory, ETH Zurich, 8093 Zurich, Switzerland, ${ }^{3}$ Laboratory of Inorganic Chemistry, ETH Zurich, 8093 Zurich, Switzerland, ${ }^{4}$ Hitachi Zosen Inova AG, Hardturmstrasse 127,8037 Zurich, Switzerland, ${ }^{5}$ KEBAG Municipal Waste Treatment Plant of Canton of Solothurn, 4528 Zuchwil, Switzerland, ${ }^{6}$ Group of Chemical Processes and Materials, Paul Scherrer Institute, 5232 Villigen PSI, Switzerland. *e-mail: wstark@ethz.ch
} 


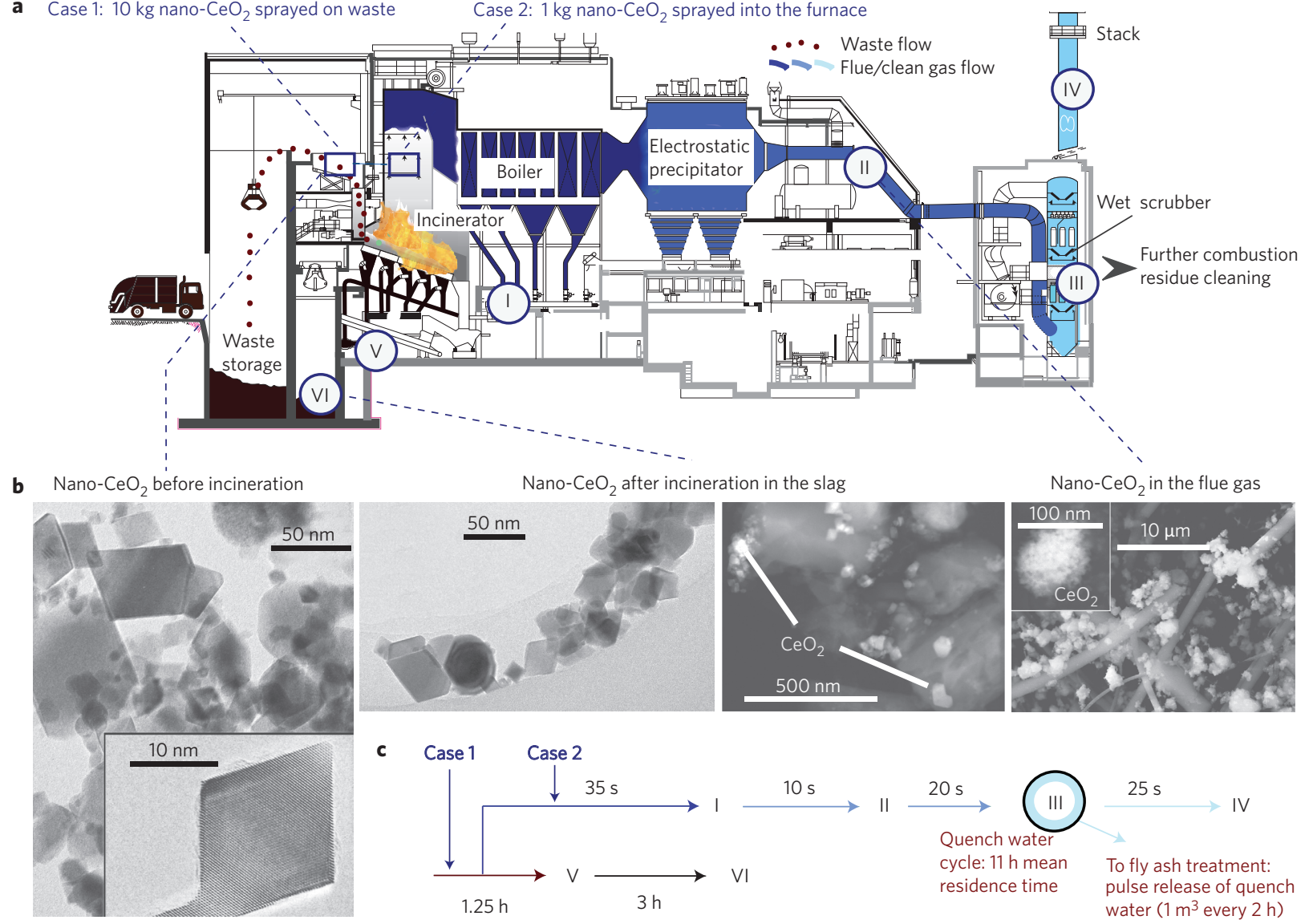

Figure 1 | Detection of $\mathrm{CeO}_{2}$ nanoparticles in all solid and fluid waste combustion residues. $\mathbf{a}$, $\mathrm{Nano}^{-\mathrm{CeO}_{2}}$ was mixed with a waste stream $\left(7 \mathrm{t} \mathrm{h}^{-1}\right)$ by spraying the nanoparticles into the prefurnace storage container (10 kg, case 1), or by spraying them into the flue gas stream above the furnace (1 kg, case 2$)$. Fly ash, quench water, flue gas after it had passed the electrostatic precipitator, slag, clean gas and slag water were sampled at locations I-IV before, during and after the addition of nanoparticles. b, Representative TEM, HAADF-STEM, and SEM images of 10-50 nm engineered crystalline nano-CeO ${ }_{2}$ particles from the different sampling locations indicated in a. c, Schematic showing the expected travel times of nano- $\mathrm{CeO}_{2}$ in the flue gas (in seconds, blue arrows; lighter colours indicate cleaner gas) and in the solid phase (in hours, brown arrows).

suspension in $\mathrm{H}_{2} \mathrm{O}$ (concentration, $5 \mathrm{wt} \% ; 10 \mathrm{~kg} \mathrm{CeO}_{2}$ ) onto $\sim 7 \mathrm{t}$ of waste in the furnace entrance over $1 \mathrm{~h}$. In case 2 , we injected $0.1 \mathrm{~m}^{3}$ of diluted nano- $\mathrm{CeO}_{2}$ suspension in $\mathrm{H}_{2} \mathrm{O}$ (concentration, $1 \mathrm{wt} \%$; $1 \mathrm{~kg} \mathrm{CeO}$ ) directly into the space above the furnace over $2.75 \mathrm{~h}$. These settings represent worst-case scenarios with an exceptionally high input of unattached nanoparticles (case 1) or an extremely high particle transfer to the gas phase to test the removal efficiency of the flue gas treatment (case 2). We focused on the gas phase because nanoparticle emissions to air are seen as problematic from a human health perspective ${ }^{16,17}$.

Flue gas was sampled after the electrostatic precipitator, and clean gas was sampled after the wet scrubber. We also collected samples from the fly ash (flue gas residues from the boiler and electrostatic precipitator), slag (solid combustion residues from the furnace grate), slag water (for the rapid cooling of the hot slag) and quench water (discharge from the wet scrubber). We measured cerium background concentrations as well as the gaseous and fluid flows. To calculate the solid flows, we used monthly measurements. We performed the experiment with stringent personal protection measures while constantly measuring personal exposure at the workplaces.

All samples were processed, digested and quantitatively analysed for cerium content using inductively coupled plasma mass spectrometry (ICP-MS, Supplementary Table S2-S8,S11,S12). We used electron microscopy (scanning electron microscopy (SEM), energy-dispersive X-ray spectroscopy (EDXS), transmission electron microscopy (TEM) and high-angle annular dark-field scanning transmission electron microscopy (HAADF-STEM)) at a maximal resolution of $0.2 \mathrm{~nm}$ to characterize the structure, composition and morphology of nano- $\mathrm{CeO}_{2}$ in the initial suspension, slag and gases (Supplementary Fig. S5).

In the small-scale experiment, we sprayed three different sizes of nano- $\mathrm{CeO}_{2}\left(d_{50}=16 \mathrm{~nm}, 83 \mathrm{~nm}, 1,600 \mathrm{~nm}\right)$ onto sawdust, which represents a waste matrix $\left(\sim 20 \% \mathrm{w} / \mathrm{w} \mathrm{CeO}_{2}\right.$; total weight, $60 \mathrm{mg}$, dry). We combusted the samples in a small-scale furnace and used a combination of a thermogravimetric analyser with an inductively coupled plasma optical emission spectrometry (ICPOES) for the continuous measurement of carbon and cerium ${ }^{18,19}$. We attached silica filters to the exhaust gas for the subsequent analysis with SEM and EDXS. Finally, we analysed the incineration residues remaining on the incineration bed with TEM and EDXS to investigate morphological changes in the nano- $\mathrm{CeO}_{2}$.

After subtracting the cerium background concentration ( $30 \mu \mathrm{g} \mathrm{g}^{-1}$ in slag, $42 \mu \mathrm{g} \mathrm{g}^{-1}$ in fly ash, $5 \mathrm{ng} \mathrm{g}^{-1}$ in quench water and $<1 \mathrm{ng} \mathrm{m}^{-3}$ in clean gas), we recovered $39 \%$ (case 1 ) and $34 \%$ (case 2) of the cerium input during the sampling period (Fig. 2a,b, Supplementary Table S12). These values are high in view of the complexity of the system, the point emission, the extremely low nanoparticle concentrations (in the microgram range) and the high waste flow of $7 \mathrm{th}^{-1}$, as well as the compromise 

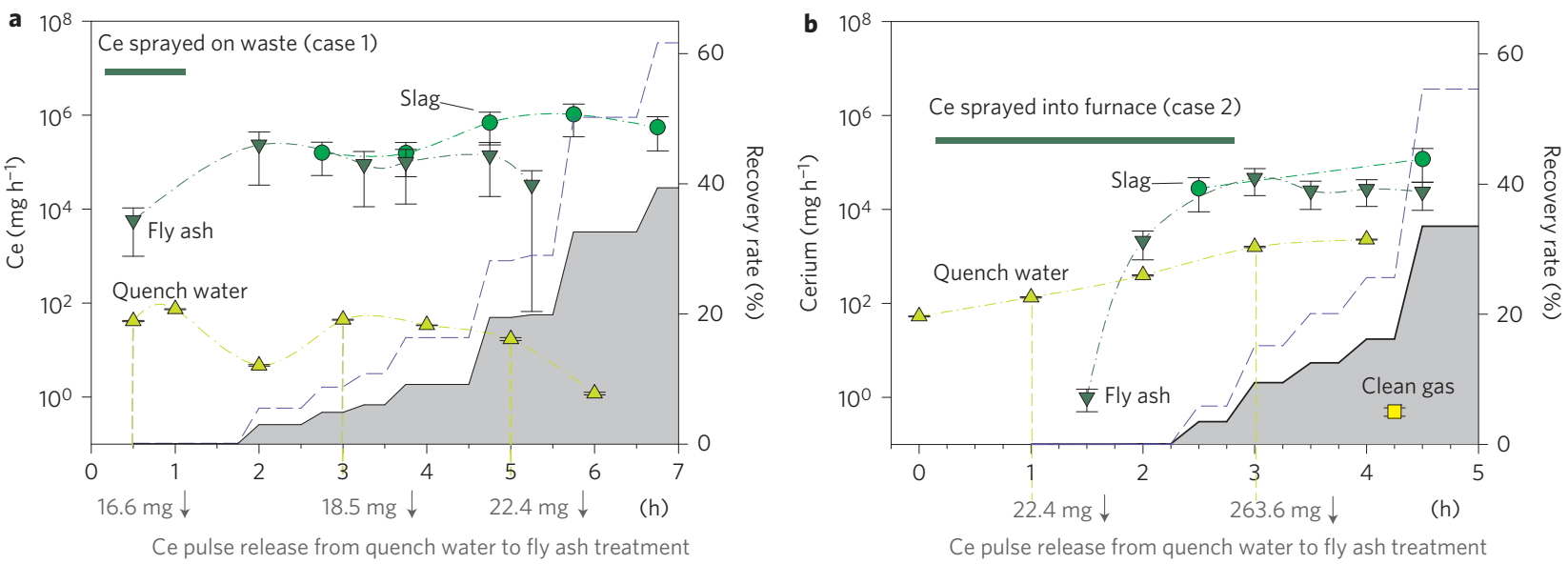

Figure 2 | Quantification of the flows of cerium in all combustion residues. Cerium flows in all combustion residues increased, and the main cerium fraction was found in the slag and fly ash. $\mathbf{a}$, Cerium flow and cumulated cerium recovery rate for the case where nano- $\mathrm{CeO}_{2}$ was sprayed onto the waste. $\mathbf{b}$, Cerium flow and cumulated cerium recovery rate for the case where nano- $\mathrm{CeO}_{2}$ was sprayed into the furnace. For $\mathbf{a}$ and $\mathbf{b}$, the green horizontal bars indicate the time period for the addition of nano- $\mathrm{CeO}_{2}$. Cerium detection and quantification was carried out for more than $5 \mathrm{~h}$ ( $x$ axis). The cumulative cerium recovery rate (grey area) is mainly determined by the recovery of cerium in the slag and fly ash. Every $2 \mathrm{~h}, 2 \mathrm{~m}^{3}$ of quench water leaves the system and removes cerium to the wastewater treatment (quantified in the olive coloured arrows). Error bars and the blue dashed line (cumulative cerium recovery rate) include measurement uncertainty, heterogeneity of the samples and variability of the combustion residues.

in the temporal resolution of the analysed samples. Although the quantified cerium flow in the gas streams is a very robust value, we have larger uncertainties in the solid fraction. The undetected cerium fraction most probably remained in the solid combustion residues, and this is supported by the small-scale experiment because no cerium was detected in the flue gas of the small-scale incinerator (see Supplementary Methods and Supplementary Figs S9,S10 and Tables S9,S10). Moreover, we could not detect a single nano- $\mathrm{CeO}_{2}$ particle on the exhaust filters with SEM/EDXS, which means that no volatilization or entrainment of the nano- $\mathrm{CeO}_{2}$ occurred.

The electrostatic precipitator in the large-scale experiment removed the nano- $\mathrm{CeO}_{2}$ from the flue gas with $>99.6 \%$ efficiency in case 2 and $>99.9 \%$ in case 1 . In case 1 , over $6 \mathrm{~h}, 0.04 \mathrm{~g}$ $(0.0005 \%)$ cerium was found in the flue gas sampled after passing through the electrostatic precipitator; in case 2, $0.47 \mathrm{~g}(0.06 \%)$ cerium had passed through the electrostatic precipitator over $4 \mathrm{~h}$ (Supplementary Fig. S7). The wet scrubber removed cerium with an efficiency of $>99.9 \%$. The mass of cerium on the measurement filters in the clean gas was below the detection limit of $0.6 \mathrm{ng}$ per measurement filter in case 1 , but we quantified up to $0.499 \pm 0.099 \mathrm{mg} \mathrm{h}^{-1}$ cerium in the clean gas stream in case 2 . Peak concentrations in the clean gas occurred at the same time as maximal cerium concentration of $0.14 \mathrm{mg} \mathrm{l}^{-1}$ in the quench water (Fig. 2b). The precise gas flow and quench water flow measurements allowed us to quantify a transfer coefficient of $0.0001 \%$ from the incinerator to the emitted purified gas. We conclude that electrostatic precipitators and particularly wet flue gas purification systems remove the nano-oxides effectively, so no relevant nano$\mathrm{CeO}_{2}$ emissions to air are expected from thermal waste treatment plants equipped with state-of-the-art flue gas cleaning systems.

In the clean gas, the maximal cerium concentration of $10 \mathrm{ng}$ per sampling filter was too low for visual detection. The nano- $\mathrm{CeO}_{2}$ particles detected in the flue gas precipitated as loose agglomerates onto the filter (Fig. 1b). Analysis by SEM, TEM, HAADF-STEM and EDXS revealed little to no changes in morphology with respect to the initially injected material (Fig. 1b, Supplementary Fig. S5). Furnace temperatures up to $1,200^{\circ} \mathrm{C}$, rapidly changing reductive and oxidative conditions and the presence of numerous chemical compounds (made of almost all naturally occurring elements) did not lead to substantial physical or chemical transformation of the particles. Even though $\mathrm{CeO}_{2}$ is known to be inert with a high melting temperature $\left(2,500{ }^{\circ} \mathrm{C}\right)$, this observation is still surprising and important, because commonly occurring matrix effects, sintering and strong interactions with oxidants would usually lead to physical or chemical transformations. Moreover, such influences are insufficiently captured with theoretical calculations (Supplementary Figs S11-S13, Table S15) or small-scale experiments (Supplementary Figs S9,S10).

In both experiments we found the majority of the recovered cerium in the solid combustion residues (Fig. 3). In case 1, most of the nano- $\mathrm{CeO}_{2}$ input was transferred to the slag via the furnace grate. We observed the peak cerium flow in case 1 in the slag after $4 \mathrm{~h}$ (Figs 1c, 2a), with a measured cerium concentration of $835 \mu \mathrm{g} \mathrm{g}^{-1}$. More cerium was in the slag than in the fly ash in case 1 , but in case 2 we observed almost equal amounts of cerium in both slag and fly ash (Fig. 3). In case 2, the nano- $\mathrm{CeO}_{2}$ was drawn immediately to the boiler and to the electrostatic precipitator after injection in the gas above the furnace. The only route to the slag is from the first section of the boiler via the fly ash (Fig. 1). Analysis showed that in both cases, the nano- $\mathrm{CeO}_{2}$ remained unchanged as crystalline particles in loose agglomerates on the surface of the slag matrix (Fig. 2b).

The quasi-closed water quenching system of the wet scrubber had a mean cerium retention time of $11 \mathrm{~h}$ with pulse releases every $2 \mathrm{~h}$. In these events, $\sim 10 \%$ of the total quench water is discharged to the fly ash treatment system. In parallel with the nano$\mathrm{CeO}_{2}$ input in case 2 , the concentration of cerium in the quench water cycle increased steadily, and continued to do so $1 \mathrm{~h}$ after cerium input (Fig. 2a,b, Supplementary Fig. S8). In case 1, the cerium concentration decreased rapidly due to the washout that started $2 \mathrm{~h}$ after the nano- $\mathrm{CeO}_{2}$ input. After combustion, the slag is transferred through a slag sump to cool down and promote compaction. Loose nano- $\mathrm{CeO}_{2}$ dispersed in this reservoir $\left(4 \mathrm{~m}^{3}\right.$ slag water) with a mean retention time of $9.6 \mathrm{~h}$ and was continuously transferred to the slag bunker. We measured a cerium background concentration of $0.6 \mathrm{ng} \mathrm{g}^{-1}$ in the slag water in all cases. This concentration steadily increased to $5.4 \mathrm{ng} \mathrm{g}^{-1}$ in case 1 . In case 2 , the cerium concentrations remained at the background level. Therefore, the absolute mass of cerium in the slag water is insignificant in comparison to the cerium found in the 


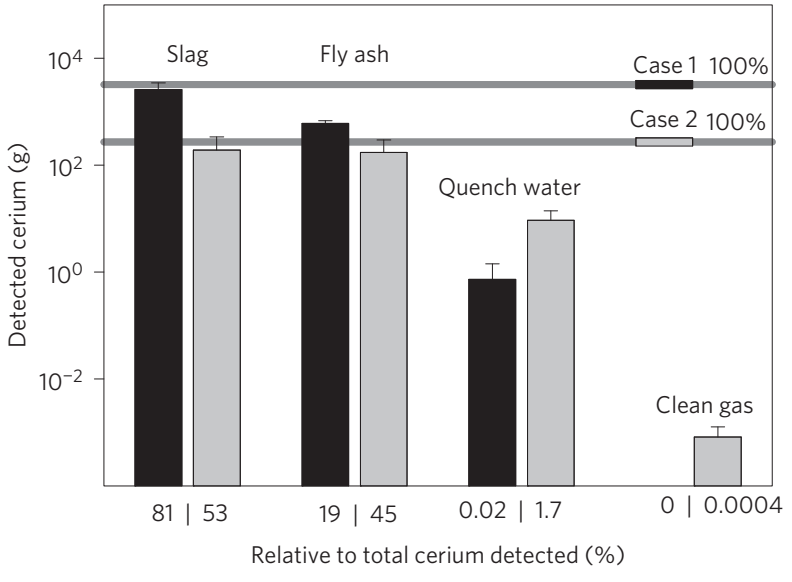

Figure 3 | Relative and absolute recovered mass of cerium in the combustion residues. The added $10 \mathrm{~kg}$ nano- $\mathrm{CeO}_{2}$ (case 1 ) and $1 \mathrm{~kg}$ nano$\mathrm{CeO}_{2}$ (case 2) are mainly transferred to the slag, fly ash and the quench water. Along the cleaning steps, cerium mass decreased by orders of magnitude. Error bars include measurement uncertainty, heterogeneity of the samples and residue flow variability.

slag. Moreover, the decrease in cerium flow in all analysed residues with retention times $<12 \mathrm{~h}$ in case 1 validates the assumption of independency of the two cases.

We observed a considerable carryover of cerium in all investigated solid, fluid and gaseous residues (Fig. 2a,b) compared to the expected peak concentrations (Fig. 1c, Supplementary Fig. S4). As nanoparticles have large surface-to-volume ratios, they tend to adhere to surfaces in the furnace chamber, boilers, heat exchanger tubes and the wet scrubber. This increases their travel time through the system. Care therefore needs to be taken during maintenance operations in plants, as workers may be exposed to nanoparticles trapped in the system. Inhalable dust measurements taken during and after this investigation showed only slightly increased concentrations of $0.04-0.33 \mathrm{mg} \mathrm{m}^{-3}$ at the slag and fly ash sampling points compared to the background concentration of $0.04 \mathrm{mg} \mathrm{m}^{-3}$ (Supplementary Table S13). The share of cerium was $0.04-0.27 \%$ of the total inhalable dust. During application of the nano- $\mathrm{CeO}_{2}$ onto the waste (case 1), we observed increased dust concentrations ( $1.43 \mathrm{mg} \mathrm{m}^{-3}$ containing $0.09 \%$ cerium).

In contrast to the small-scale experiment, where we were not able to observe an entrainment or volatilization of nano- $\mathrm{CeO}_{2}$, we did find nanoparticles in the flue gas of the full-scale incineration plant. Reassuringly, modern solid-waste incinerators efficiently remove engineered nanoparticles from flue gas and the emitted clean gas poses no risk to the environment. However, these plants are not an effective end-of-life treatment for highly stable engineered nanoparticles such as nano- $\mathrm{CeO}_{2}$; instead, they shift the disposal problem to subsequent processing steps, landfills and final deposits where the slag and fly ash residues are eventually handled and stored. Furthermore, engineered nanoparticle emissions can occur during further treatment of slag such as material recovery, transportation and intermediate storage. In recent years, in particular, there has been an increasing trend towards the use of mechanical technologies to separate and recover metals (for example, copper and aluminium) from slag, or even so-called landfill mining. Although such technologies are prime examples of industrial ecology and represent a great advancement towards closing material cycles and increasing resource efficiency, the results of this study indicate that engineered nanoparticles may be released into the air during the recovery process and thus may lead to increased worker exposure. Similarly, filter ash is increasingly used as a resource for the recovery of metals (zinc, lead) through acid washing. The fate of engineered nanoparticles during this process, including washouts into wastewater streams, and the subsequent metallurgical process is unclear and represents a potential risk. Application of the precautionary principle therefore dictates a careful evaluation of the use of persistent nanomaterials in consumer products and reveals great similarities between the earlier risk discussions on persistent chemicals or gases and the current discussion on nanoecotoxicology.

\section{Methods \\ Large-scale incinerator. We conducted nano- $\mathrm{CeO}_{2}$ inputs and residue samplings in the municipal solid-waste incineration plant Emmenspitz (Zuchwil, Switzerland; Fig. 1a). This plant makes use of a flue gas treatment found in modern waste incinerators such as electrostatic precipitation, as well as wet flue gas treatment. Each year, 220,000 t of waste are incinerated in four furnaces, resulting in 50,744 t of slag. We selected the furnace of line 3 for the nano- $\mathrm{CeO}_{2}$ inputs; this furnace has an incineration capacity of $8.5 \mathrm{t} \mathrm{h}^{-1}$ and an average slag output of $1,850 \mathrm{~kg} \mathrm{~h}^{-1}$. An electrostatic precipitator with an installed capacity of $57,200 \mathrm{~N} \mathrm{~m}^{3} \mathrm{~h}^{-1}$ removes the fly ash after it has passed through the boiler (which serves for energy recovery). The flue gas is then drawn through a wet scrubber with selective non-catalytic $\mathrm{NO}_{x}$ reduction, and an activated carbon treatment for dioxine removal. The fly ash ( $450 \mathrm{~kg} \mathrm{~h}^{-1}, 140 \mathrm{~kg}$ per line per hour, 3,847 t per year) is mixed with the acidic eluate from the wet scrubber. The remaining fluids are pretreated (flocculation and precipitation) and then released into the wastewater stream.}

Addition, sampling and analytics of the nano- $\mathrm{CeO}_{2}$ particles. $\mathrm{CeO}_{2}$ nanoparticles were manufactured using flame spray synthesis ${ }^{20}$ with carboxylate precursors ${ }^{21}$, and were dispersed in ultrapure, filtrated water (Millipore, S185, resistance $>18.2 \mathrm{M} \Omega \mathrm{cm}$ ) at a concentration of either $5 \mathrm{wt} \%$ or $1 \mathrm{wt} \%$. A detailed description and characterization of the nanoparticles can be found in the Supplementary Information. At the incineration plant, we took control samples of all investigated fractions. The sampling plan is shown in Supplementary Fig. S4. In case 1, we sprayed $10 \mathrm{~kg}$ nano- $\mathrm{CeO}_{2}$ suspended in $0.2 \mathrm{~m}^{3} \mathrm{H}_{2} \mathrm{O}$ onto the waste in the feed hopper for $60 \mathrm{~min}$ (Supplementary Fig. S3). We fed $1 \mathrm{~kg}$ nano- $\mathrm{CeO}_{2}$ suspended in $0.1 \mathrm{~m}^{3}$ water through the ammonia nozzles directly into the furnace in case 2 . Estimated residence times in the incinerator (Fig. 1c) are based on tracer studies (with metals other than cerium) as well as expert opinion. The exact sampling procedure, sample preparation and analysis with ICP-MS and electron microscopy are described in the Supplementary Information.

Indoor exposure measurements. The control room in the incineration plant is mechanically ventilated and under slight overpressure. The waste bunker and the waste feeding zone are under slight underpressure. Average temperature is $23 \pm 2{ }^{\circ} \mathrm{C}$, relative humidity is $26 \%(20-30 \%)$ and air pressure (decreasing over time) is 980-970 mbar. We sampled the inhalable dust fraction with silica filters with the GSP-10 system according to a standard procedure (SAA 1.007, SUVA Swiss National Accident Insurance Fund) with differentiation characteristic according to EN-481 22 . Further details about the nanoparticle exposure measurements are presented in the Supplementary Information.

Small-scale incineration experiment. For the small-scale incineration experiment we sprayed samples of each $\mathrm{CeO}_{2}$-suspension size class (no overlapping size distributions, $d_{50}=16 \mathrm{~nm}, 83 \mathrm{~nm}, 1,600 \mathrm{~nm}$, measured with a Lumisizer) onto 2-4 g sawdust (mimicking the waste matrix). The dried samples contained $15-22 \% \mathrm{w} / \mathrm{w}$ nano- $\mathrm{CeO}_{2}$. The combustion was carried out in a furnace (Mettler TGA/SDTA851, temperature up to $950{ }^{\circ} \mathrm{C}, 8.5 \% \mathrm{O}_{2}$ ). We used a thermogravimetric analyser in combination with an ICP-OES (Varian Liberty 110). A detailed description of the method and analysis is found in the Supplementary Information.

Further details, including tables and figures, are presented in the Supplementary Information.

Received 24 January 2012; accepted 5 April 2012; published online 20 May 2012

\section{References}

1. European Commission. Eurostat: waste statistics; available at http:/ /epp.eurostat.ec.europa.eu (accessed May 2011).

2. Dang, Y., Zhang, Y., Fan, L., Chen, H. \& Roco, M. Trends in worldwide nanotechnology patent applications: 1991 to 2008. J. Nanopart. Res. 12, 687-706 (2010).

3. Hoornweg, D. \& Lam, P. in Urban Development Working Papers 9, 156 (World Bank, 2005).

4. Cheng, H. \& Hu, Y. Municipal solid waste (MSW) as a renewable source of energy: current and future practices in China. Biores. Technol. 101, 3816-3824 (2010)

5. Council of the European Parliament. Council Directive 1999/31/EC of 26 April 1999 on the Landfill of Waste (Council of the European Parliament, 1999). 
6. Stark, W. J. Nanoparticles in biological systems. Angew. Chem. Int. Ed. 50, 1242-1258 (2011).

7. Anderson, J. G., Toohey, D. W. \& Brune, W. H. Free radicals within the Antarctic vortex: the role of CFCs in Antarctic ozone loss. Science 251, 39-46 (1991).

8. Peto, J., Decarli, A., La Vecchia, C., Levi, F. \& Negri, E. The European mesothelioma epidemic. Br. J. Cancer 79, 666-672 (1999).

9. Muir, D. C. G. Organochlorine contaminants in arctic marine food chains: accumulation of specific polychlorinated biphenyls and chlordane-related compounds. Environ. Sci. Technol. 22, 1071-1079 (1988).

10. Limbach, L. K. et al. Removal of oxide nanoparticles in a model wastewater treatment plant: influence of agglomeration and surfactants on clearing efficiency. Environ. Sci. Technol. 42, 5828-5833 (2008).

11. Kiser, M. A. et al. Titanium nanomaterial removal and release from wastewater treatment plants. Environ. Sci. Technol. 43, 6757-6763 (2009).

12. Buonanno, G., Stabile, L., Avino, P. \& Belluso, E. Chemical, dimensional and morphological ultrafine particle characterization from a waste-to-energy plant. Waste Manage. 31, 2253-2262 (2011).

13. Mueller, N. C. \& Nowack, B. Exposure modeling of engineered nanoparticles in the environment. Environ. Sci. Technol. 42, 4447-4453 (2008).

14. Belevi, H. \& Moench, H. Factors determining the element behavior in municipal solid waste incinerators. 1. Field studies. Environ. Sci. Technol. 34, 2501-2506 (2000).

15. Belevi, H. \& Langmeier, M. Factors determining the element behavior in municipal solid waste incinerators. 2. Laboratory experiments. Environ. Sci. Technol. 34, 2507-2512 (2000).

16. Nel, A., Xia, T., Madler, L. \& Li, N. Toxic potential of materials at the nanolevel. Science 311, 622-627 (2006).

17. Oberdörster, G., Oberdörster, E. \& Oberdörster, J. Nanotoxicology: an emerging discipline evolving from studies of ultrafine particles. Environ. Health Perspect. 113, 823-839 (2005).

18. Ludwig, C., Lutz, H., Wochele, J. \& Stucki, S. Studying the evaporation behavio of heavy metals by thermo-desorption spectrometry. Fresenius J. Anal. Chem. 371, 1057-1062 (2001).

19. Ludwig, C., Wochele, J. \& Jörimann, U. Measuring evaporation rates of metal compounds from solid samples. Anal. Chem. 79, 2992-2996 (2007).
20. Mädler, L., Stark, W. J. \& Pratsinis, S. E. Flame-made ceria nanoparticles. J. Mater. Res. 17, 1356-1362 (2002).

21. Stark, W. J., Madler, L., Maciejewski, M., Pratsinis, S. E. \& Baiker, A. Flame synthesis of nanocrystalline ceria-zirconia: effect of carrier liquid. Chem. Commun. 588-589 (2003).

22. Deutsches Institut für Normung e.V. EN 481:1993 9, German version, http://shop.bsigroup.com/ProductDetail/?pid=000000000000313177 (Deutsches Institut für Normung e.V., 1993).

\section{Acknowledgements}

The authors thank S. Halim, N. Luechinger, P. Ammann, R. Frey, L. Morf, A. Schuler, M. Tellenbach and C. Raptis for technical support. Electron microscopy was performed at the Electron Microscopy Center of the ETH Zurich (EMEZ), Switzerland. Financial support and approval of the study was provided by State Secretariat for Economic Affairs SECO (L. Bergamin, C. Rueegg), the Federal Office for the Environment FOEN (A. Hauser, K. Schenk, C. Müller Beat, R. Quartier) and Swiss Accident Insurance SUVA (C. Bosshard, P. Steinle). Funding from 'Prosuite', a research project under the Seventh Framework Program of the European Commission (ref. no. 227078), is gratefully acknowledged.

\section{Author contributions}

L.L. initiated the project and designed the study, supported by A.S., M.J., K.P. and T.W. E.E. and D.S were involved in sampling and sample preparations. B.H., R.B. and L.F. performed the ICP-MS analysis. F.K. performed electron microscopy analysis. C.L. led the thermodynamic calculations. M.R. was responsible for nanoparticle suspension preparation. D.G., S.H. and W.J.S. co-wrote the manuscript. T.W. was involved in planning and conducting the study, analysed data and co-wrote the manuscript.

\section{Additional information}

The authors declare no competing financial interests. Supplementary information accompanies this paper at www.nature.com/naturenanotechnology. Reprints and permission information is available online at http://www.nature.com/reprints. Correspondence and requests for materials should be addressed to W.J.S. 